CLINICAL STUDY

\title{
Long-term effects of previous oxandrolone treatment in adult women with Turner syndrome
}

Kim Freriks, Theo C J Sas ${ }^{1,2}$, Maaike A F Traas ${ }^{3}$, Romana T Netea-Maier, Martin den Heijer, Ad R M M Hermus, Jan M Wit ${ }^{4}$, Janiëlle A E M van Alfen-van der Velden ${ }^{5}$, Barto J Otten ${ }^{5}$, Sabine M P F de Muinck Keizer-Schrama ${ }^{2}$, Martin Gotthardt ${ }^{6}$, Philippe H Dejonckere ${ }^{7}$, Gladys R J Zandwijken ${ }^{8}$, Leonie A Menke ${ }^{4,9}$ and Henri J L M Timmers Department of Endocrinology (471), Radboud University Nijmegen Medical Centre, PO Box 9101, 6500 HB Nijmegen, The Netherlands, ${ }^{1}$ Department of Paediatrics, Albert Schweitzer Hospital, Dordrecht, The Netherlands, ${ }^{2}$ Department of Paediatrics, Erasmus Medical Centre, Rotterdam, The Netherlands, ${ }^{3}$ Department of Obstetrics and Gynaecology, Gelre Hospital Apeldoorn, Apeldoorn, The Netherlands, ${ }^{4}$ Department of Paediatrics, Leiden University Medical Center, Leiden, The Netherlands, ${ }^{5}$ Department of Paediatrics, Radboud University Nijmegen Medical Centre, Nijmegen, The Netherlands, ${ }^{6}$ Department of Nuclear Medicine, Radboud University Nijmegen Medical Centre, Nijmegen, The Netherlands, ${ }^{7}$ Department of Phoniatrics, University Medical Centre Utrecht, Utrecht, The Netherlands, ${ }^{8}$ Dutch Growth Research Foundation, Rotterdam, The Netherlands and ${ }^{9}$ Department of Paediatrics, Haga Hospital, The Hague, The Netherlands

(Correspondence should be addressed to K Freriks; Email: k.freriks@aig.umcn.nl)

\begin{abstract}
Objective: Short stature is a prominent feature of Turner syndrome (TS), which is partially overcome by $\mathrm{GH}$ treatment. We have previously reported the results of a trial on the effect of oxandrolone $(\mathrm{Ox})$ in girls with TS. Ox in a dose of $0.03 \mathrm{mg} / \mathrm{kg}$ per day (Ox 0.03) significantly increased adult height gain, whereas Ox mg/kg per day (0.06) did not, at the cost of deceleration of breast development and mild virilization. The aim of this follow-up study in adult participants of the pediatric trial was to investigate the long-term effects of previous Ox treatment.

Design and methods: During the previous randomized controlled trial, 133 girls were treated with GH combined with placebo $(\mathrm{Pl})$, Ox 0.03, or Ox 0.06 from 8 years of age and estrogen from 12 years. Sixtyeight women ( $\mathrm{Pl}, n=23$; Ox 0.03, $n=27$; and $\mathrm{Ox} 0.06, n=18)$ participated in the double-blind followup study (mean age, 24.0 years; mean time since stopping GH, 8.7 years; and mean time of Ox/Pl use, 4.9 years). We assessed height, body proportions, breast size, virilization, and body composition. Results: Height gain (final minus predicted adult height) was maintained at follow-up (Ox 0.0310 .2 $\pm 4.9 \mathrm{~cm}$, Ox $0.069 .7 \pm 4.4 \mathrm{~cm}$ vs Pl $8.0 \pm 4.6 \mathrm{~cm}$ ). Breast size, Tanner breast stage, and body composition were not different between groups. Ox-treated women reported more subjective virilization and had a lower voice frequency.

Conclusion: Ox $0.03 \mathrm{mg} / \mathrm{kg}$ per day has a beneficial effect on adult height gain in TS patients. Despite previously reported deceleration of breast development during Ox 0.03 treatment, adult breast size is not affected. Mild virilization persists in only a small minority of patients. The long-term evaluation indicates that $\mathrm{Ox} 0.03$ treatment is effective and safe.
\end{abstract}

European Journal of Endocrinology 168 91-99

\section{Introduction}

Turner syndrome (TS) has an incidence of $\sim 1$ in 2000 live born girls and is the result of complete or partial absence of one X chromosome (1). Short stature, together with ovarian failure and dysmorphic features, is one of the most prominent aspects. Without GH treatment, adult women with TS are on average $20 \mathrm{~cm}$ shorter than women without TS (2). Although TS is not associated with $\mathrm{GH}$ deficiency, supraphysiological GH doses increase adult height by $5-12 \mathrm{~cm}(3,4,5)$. Differences in efficacy of GH treatment can be explained by age at initiation and duration of therapy, compliance, estrogen therapy regimen, and several, partly unknown, genetic factors $(4,6,7)$.
Oxandrolone $(\mathrm{Ox})$ is a synthetic non-aromatizable anabolic steroid with weak virilizing effects compared with testosterone. Ox has been shown to increase adult height and growth velocity in TS $(8,9,10,11,12,13$, 14). Some of the initial studies used Ox dosages of $0.1 \mathrm{mg} / \mathrm{kg}$ per day or higher, which were subsequently lowered due to virilization and early bone maturation $(9,10,11)$.

We have previously reported the results of a randomized placebo-controlled double-blind trial on the effect of the addition of $\mathrm{Ox}$ in lower dosages to standard $\mathrm{GH}$ and estrogen treatment in girls with TS (12). Intention to treat analysis showed that compared with $\mathrm{GH}+$ placebo $(\mathrm{Pl}), \mathrm{GH}+\mathrm{Ox}$ in a dose of $0.03 \mathrm{mg} / \mathrm{kg}$ per day (Ox 0.03) increased adult height gain - final 
minus predicted adult height $-(9.5 \mathrm{vs} 7.2 \mathrm{~cm}$ in $\mathrm{Pl})$ at the cost of mild deceleration of breast development. At a higher dose of $0.06 \mathrm{mg} / \mathrm{kg}$ per day (Ox 0.06), no significant increase in height gain was found (8.3 vs $7.2 \mathrm{~cm}$ in $\mathrm{Pl}$ ), probably due to faster bone maturation and premature discontinuation of $\mathrm{Ox}$ because of virilizing side effects. In the Ox 0.06 group, significantly more girls reported subjective virilization. Findings in both Ox groups included a decrease in fat mass, an increase in muscle mass, and lowering of the voice pitch, which were initially in the higher range, to normal voice frequencies in most cases $(15,16)$. To assess whether these effects were transient or definitive, we conducted this follow-up study. We investigated the long-term side effects of $\mathrm{Ox}$ in the two different dosages (0.03 and $0.06 \mathrm{mg} / \mathrm{kg}$ per day) compared with $\mathrm{Pl}$ in GH- and estrogen-treated TS women several years after discontinuation of $\mathrm{GH}$ and $\mathrm{Ox}$ therapy. We examined height, body proportion and composition, virilization (including voice frequency), and breast development.

\section{Materials and methods}

\section{Participants and previous treatment}

Participants of the initial pediatric, randomized, doubleblind, placebo-controlled trial were recruited between 1991 and 2003 in ten pediatric endocrine centers in The Netherlands (12). Inclusion criteria were a TS compatible karyotype (except for cytogenetical evidence of Y-chromosomal material), a calendar age between 2.00 and 15.99 years, and a bone age younger than 12.00 years. Exclusion criteria were growth failure due to other causes, use of medication that could interfere with study medication, and previous $\mathrm{GH}$ or sex steroid therapy.

In total, 133 girls were included and assigned to age group 1 (2.00-7.99 years), 2 (8.00-11.99 years), or 3 (12.00-15.99 years). After stratification for calendar age and height SDS, they were randomized and blindly assigned to receive $\mathrm{Ox} 0.03$, Ox 0.06 , or $\mathrm{Pl}$ orally at bedtime after reaching the age of 8 years. Furthermore, the girls were treated with $\mathrm{GH}\left(1.33 \mathrm{mg} / \mathrm{m}^{2}\right.$ per day $)$ from baseline and, when spontaneous puberty was absent, with estrogen from the age of 12 years. $17-\beta$ Estradiol $\left(\mathrm{E}_{2}\right)$ was prescribed in age groups 1 and 2 and ethinylestradiol in age group $3(5$ and $0.05 \mu \mathrm{g} / \mathrm{kg}$ per day orally, increasing to 10 and $0.1 \mu \mathrm{g} / \mathrm{kg}$ per day after 2 years respectively). When ethinylestradiol became unavailable in 2002, $\mathrm{E}_{2}$ was also prescribed in age group 3. For more detailed participant information, randomization, and treatment modalities, see Menke et al. (12).

All participants in the original trial were eligible for inclusion in the current follow-up study, provided that they had been off GH treatment at least 6 months before the investigation. Additional exclusion criteria for the follow-up study were participation in another drug study within 2 months of entry, malignancy, severely disabling disease, psychiatric illness, and current pregnancy or fertility treatment.

\section{Investigations}

Participants and investigators were blinded to the treatment arms, so data were collected in a doubleblind fashion. Participants were invited for a 1-day visit in the outpatient department of the Radboud University Nijmegen Medical Centre, Nijmegen, The Netherlands. We used a questionnaire, including an extensive medical history and questions about possible side effects, which was completed at home. All examinations were performed by a single researcher (K Freriks), except for the gynecological examinations, which were done by a gynecologist (M A F Traas).

Height Height was measured using an electronic stadiometer. Adult height gain was calculated as the mean of three height measurements minus the predicted adult height. Predicted adult height was calculated using the modified projected adult height: $146.95+6.37 \times(-0.2+0.836 \times$ height SDS at baseline) $(12,17)$. Height SDS for untreated Northern European girls with TS at adult age was calculated by (adult height-146.95)/6.37 (2).

Body composition and proportions Sitting height was measured using an electronic stadiometer and a sitting height table. Subischial leg length was calculated by height minus sitting height. Biacromial and biiliacal distance and hand and foot length were measured using a Harpenden anthropometer. Skinfolds were measured with a Harpenden skinfold caliper at the biceps, triceps, subscapular, and suprailiac level. We measured the arm span and circumferences of the head, left arm, waist, hip, and thigh with a conventional measuring tape. All measurements were performed according to Gerver (18). Body weight was measured on a scale, with the patient in underwear and barefoot. BMI was calculated by dividing weight $(\mathrm{kg})$ by squared height $\left(\mathrm{m}^{2}\right)$. Upper arm muscle area (UAMA) was calculated according to Frisancho (19): UAMA = (mid upper arm circumference $-(\pi \times$ triceps skinfold thickness $))^{2} / 4 \pi$. Total body fat percentage was calculated using the sum of four skinfolds and $c$ and $m$ values according to Durnin \& Womersley (20). Total body fat percentage was calculated by $(4.95 /(c-(m \times \log$ sum of skinfolds) $)-4.5) \times 100$. A total body dual-energy X-ray absorptiometry (DXA; Hologic QDR 4500 Densitometer, Zaventem, Belgium) was performed to estimate body composition including percentages of total body fat and lean body mass. To assess 'android' fat percentage, a region of interest spanning from the pelvis cut (lower boundary) to a line defined as $20 \%$ of the distance 
between the pelvis and neck cuts (upper boundary) was used, as defined by the manufacturer.

Breast size and sexual maturation Breast size was estimated by subtraction of the widest chest circumference (at the level of the nipples) minus the smallest chest circumference (under the breasts) with the patient in supine position. Pubertal stage was estimated according to Tanner for breast development and pubic hair (21).

Subjective virilization Subjective virilization was scored by the following questions: do you experience excessive hair growth (yes/no)? Do you suffer from acne (yes/no)? Do you experience a greasy skin (yes/no)? How do you consider your clitoral size (too small/ small/normal/large/too large)? How do you consider your voice (low/normal/high)?

Objective virilization The Ferriman and Gallwey score was used to assess hirsutism. A score of six or higher was considered as hirsutism (22). The existence of acne, greasy hair, and/or skin was scored. The gynecologist measured clitoral size (large/normal/small/absent, a clitoris size above $1 \mathrm{~cm}$ was considered large). To assess voice frequencies, recordings were performed in a quiet room. The voice recording consisted of a backward count from 10 to 0 and five standardized sentences. Both measurements were at a comfortable pitch and loudness. Fundamental voice frequency was assessed using a multidimensional voice program (Kay Elemetrics Corp., Lincoln Park, NJ, USA). Based on Traunmüller \& Eriksson (23), we considered a fundamental voice frequency below $201 \mathrm{~Hz}$ as abnormally low.

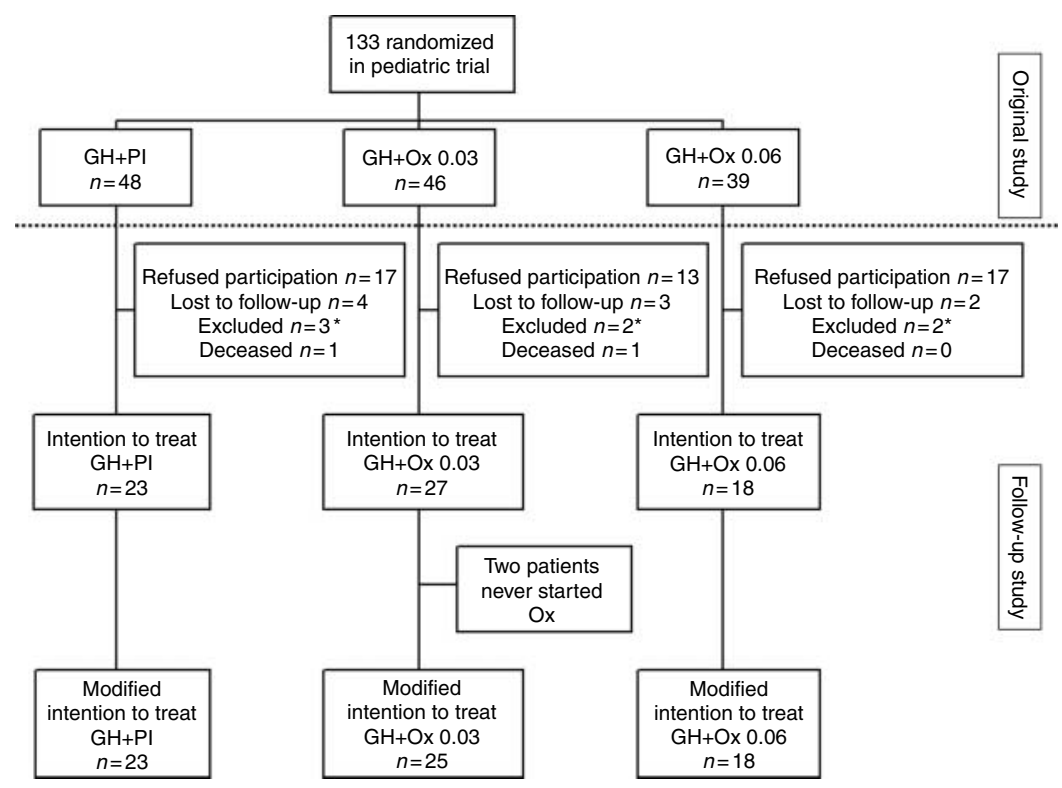

Laboratory investigations To assess long-term safety and to identify possible confounders of outcome measures, venous blood samples were assayed for lipid spectrum, kidney and liver function, glucose metabolism (fasting glucose and insulin levels and $\mathrm{HbA1c}$ ), insulin-like growth factor 1 (IGF1), androgen levels (DHEA, androstenedione, and testosterone), and thyroid function. The homeostatic model assessment index for insulin resistance was calculated according to the formula: (insulin $(\mathrm{mU} / \mathrm{l}) \times$ glucose $(\mathrm{mmol} / \mathrm{l})) / 22.5$ (24).

\section{Statistical analyses}

Differences in patient characteristics between the participants and nonparticipants of the follow-up study were assessed using Student's t-test. Differences in outcome between dosage groups were tested by linear regression using two dummies (for $\mathrm{GH}+\mathrm{Ox} 0.03$ and $\mathrm{GH}+\mathrm{Ox}$ 0.06) for continuous variables and by Pearson's $\chi^{2}$ test for nominal data. We performed an intention to treat analysis for height-related items (primary endpoint) and, in order to prevent underestimation of the side effects of $\mathrm{Ox}$, a modified intention to treat analysis, i.e. including only those patients who took at least one dose of the study medication, for the secondary endpoints (Fig. 1). A $P$ value $<0.05$ was considered significant. We used Statistical Package for the Social Sciences version 16.0 (SPSS, Inc.).

This follow-up study was conducted in accordance with the guidelines of the Declaration of Helsinki and was approved by the Ethics Committee of the Radboud University Nijmegen Medical Centre. Written informed consent was obtained for each participant.
Figure 1 Follow-up of original study participants and inclusion to the current study. ${ }^{\star}$ Exclusion in the PI group due to current $\mathrm{GH}$ treatment $(n=2)$ and multiple handicaps $(n=1)$, in the Ox 0.03 group due to current $\mathrm{GH}$ treatment $(n=2)$ and in the Ox 0.06 group due to current $\mathrm{GH}$ treatment $(n=1)$ and psychiatric illness $(n=1)$. 
Table 1 Patient characteristics of 68 patients previously treated with placebo or Ox (0.03 or $0.06 \mathrm{mg} / \mathrm{kg}$ per day).

\begin{tabular}{|c|c|c|c|c|c|}
\hline & $\mathbf{G H}+\mathbf{P I}(n=23)$ & $\begin{array}{c}\mathbf{G H}+\mathbf{O} \times \mathbf{0 . 0 3} \\
(n=27)\end{array}$ & $\begin{array}{l}\mathrm{GH}+\mathrm{O} \times 0.03 \text { vs } \\
\mathrm{GH}+\mathrm{PI}, \boldsymbol{P} \text { value }\end{array}$ & $\begin{array}{c}\mathbf{G H}+\mathbf{O} \times \mathbf{0 . 0 6} \\
(n=18)\end{array}$ & $\begin{array}{l}\mathrm{GH}+O \times 0.06 \text { vs } \\
\mathrm{GH}+\mathrm{PI}, P \text { value }\end{array}$ \\
\hline Age & $24.6 \pm 4.2$ & $23.7 \pm 3.7$ & 0.425 & $23.6 \pm 3.4$ & 0.425 \\
\hline Spontaneous puberty ${ }^{\mathrm{a}}(\%)$ & $4 / 23=17.4$ & $8 / 27=29.6$ & 0.313 & $4 / 18=22.2$ & 0.698 \\
\hline $45, X(\%)$ & $14 / 23=60.9$ & $10 / 27=37.0$ & 0.093 & $8 / 18=44.4$ & 0.295 \\
\hline HRT users ${ }^{\mathrm{b}}(\%)$ & $20 / 23=87.0$ & $24 / 27=88.9$ & 0.834 & $16 / 18=88.9$ & 0.851 \\
\hline Time since stopping GH & $8.7 \pm 3.7$ & $8.6 \pm 3.2$ & 0.916 & $8.8 \pm 3.0$ & 0.899 \\
\hline Age at starting GH & $9.9 \pm 3.7$ & $9.0 \pm 3.8$ & 0.402 & $8.6 \pm 3.0$ & 0.259 \\
\hline Age at starting $\mathrm{Ox} / \mathrm{PI}^{\mathrm{b}}$ & $10.7 \pm 2.5$ & $10.4 \pm 2.2$ & 0.593 & $9.7 \pm 1.7$ & 0.140 \\
\hline Duration of GH therapy & $5.8 \pm 2.7$ & $6.2 \pm 3.4$ & 0.601 & $6.2 \pm 2.3$ & 0.639 \\
\hline Duration of Ox/PI therapy ${ }^{c}$ & $5.1 \pm 1.6$ & $4.7 \pm 1.5$ & 0.315 & $5.0 \pm 1.3$ & 0.709 \\
\hline
\end{tabular}

HRT, hormone replacement therapy; Ox, oxandrolone.

${ }^{a}$ Defined as no need for estrogen treatment before or during $\mathrm{GH}$ treatment.

${ }^{b}$ Two patients, one in the Ox 0.03 group and one in the Ox 0.06, incorrectly used no HRT. There are no significant differences in HRT regimens. For the total group, different regimens were continuous combined $n=9$, sequential combined $n=33$, oral anticonceptive containing estrogen and progestogen $n=13$, and other $n=5$. One patient in the Ox 0.03 group used no HRT for 4 years between the original and follow-up study.

'Two patients, both in the Ox 0.03 group, never started Ox.

\section{Results}

\section{Recruitment}

Of the 133 original participants in the trial, 68 were eligible for inclusion in the follow-up study $(\mathrm{Pl}, n=23$; Ox 0.03, $n=27$; and Ox 0.06, $n=18$ ). Their data are shown in Fig. 1 and Table 1. Besides lost to follow-up $(n=9)$, excluded $(n=7)$, and deceased $(n=2)$, 47 women refused to participate. Causes of death in the two deceased patients were severe pneumonia at the age of 15 years and colorectal carcinoma at the age of 28 years. The main reasons for declining to participate were the burden of a full day of examination besides regular medical follow-up (at the cost of work or study) and travel distance. Table 2 compares the 68 participants in the follow-up study with the 65 nonparticipants. The participants used Ox for a longer period and had a higher height gain at the end of the pediatric study compared with the nonparticipants. The main results for the participants are summarized in Table 3. The mean age was $24.0 \pm 3.8$ years and the mean interval since the end of GH treatment was $8.7 \pm 3.3$ years.

\section{Height gain}

For the total group, mean adult height gain was $9.2 \pm$ $4.7 \mathrm{~cm}$ compared with $9.1 \pm 4.8 \mathrm{~cm}$ at the last visit of the pediatric trial. Differences in adult height gain between both Ox-treated groups and the Pl group were comparable with the data of the pediatric trial. Duration of Ox use was positively correlated with adult height gain $(P$ value 0.011$)$.

\section{Body composition and proportions}

Weight, BMI, and percentage lean body mass/fat mass were equal across the three treatment modalities. Regarding body proportions, sitting height-to-height ratio was higher in the $\mathrm{GH}+\mathrm{Ox} 0.06$ group. Biiliacal distance was not different between the $\mathrm{Pl}$ and Ox groups nor was biacromial distance. Hand and foot lengths were similar in all groups, but the foot length/height ratio was slightly lower, indicating relatively smaller foot length in the GH+Ox 0.03 group. Head circumference was higher in the $\mathrm{GH}+\mathrm{Ox} 0.03$ group, without difference in head circumference to height ratio. No differences in left arm, waist, hip, and left thigh circumferences were found.

\section{Breast size and sexual maturation}

Four patients underwent breast surgery: one patient underwent a breast reduction $(\mathrm{GH}+\mathrm{Ox} 0.06)$, one patient a breast enlargement $(\mathrm{GH}+\mathrm{Ox} 0.06)$, and two patients a breast reconstruction because of shape (one in the $\mathrm{GH}+\mathrm{Ox} 0.03$ group and one in the $\mathrm{GH}+\mathrm{Ox} 0.06$ group). Two additional patients did not want to have their breast size measured. These six patients were excluded from the breast size analysis. Breast size and Tanner stages did not differ between the different treatment modalities. Fifty percent of the women

Table 2 Characteristics of participants vs nonparticipants in the follow-up study.

\begin{tabular}{lccc}
\hline & $\begin{array}{c}\text { Participants } \\
(n=68)\end{array}$ & $\begin{array}{c}\text { Nonparticipants } \\
(n=65)\end{array}$ & $\boldsymbol{P}$ value \\
\hline Age at start GH & $9.2 \pm 3.6$ & $7.9 \pm 4.2$ & 0.061 \\
Age at start Ox & $10.3 \pm 2.2$ & $10.3 \pm 2.4$ & 0.947 \\
Height SDS (ref TS) start $_{\text {Duration of GH use }}{ }^{\text {a }}$ & $0.6 \pm 0.9$ & $0.3 \pm 1.0$ & 0.064 \\
Duration of Ox use $^{\text {a,b }}$ & $6.2 \pm 2.9$ & $6.9 \pm 3.5$ & 0.258 \\
Height SDS (ref TS) last $_{\quad \text { pediatric visit }}{ }^{\mathrm{a}}$ & $5.0 \pm 1.4$ & $4.3 \pm 1.8$ & 0.040 \\
Height gain last pediatric visit $^{\mathrm{a}}$ & $1.7 \pm 0.9$ & $1.2 \pm 1.0$ & 0.002 \\
45,X (\%) & $9.4 \pm 4.6$ & $7.5 \pm 4.3$ & 0.017 \\
& 47.1 & 53.9 & 0.434 \\
\hline
\end{tabular}

${ }^{\text {a}}$ Five patients in the nonparticipant group were still on $\mathrm{GH}$ treatment and four were lost to follow-up. These nine were excluded for these comparisons.

${ }^{b}$ Six patients in the nonparticipant group and two patients in the participant group never started Ox. 


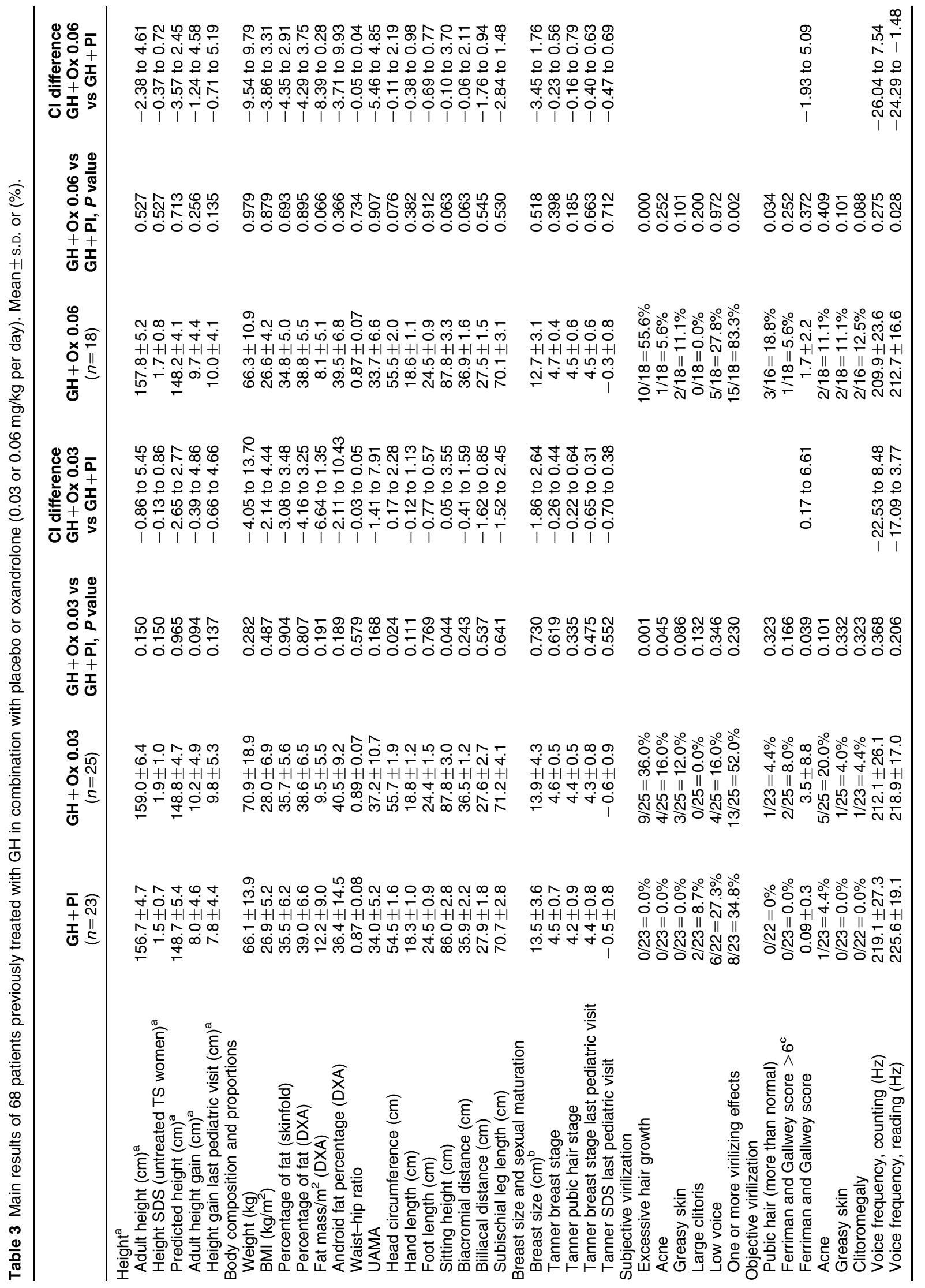




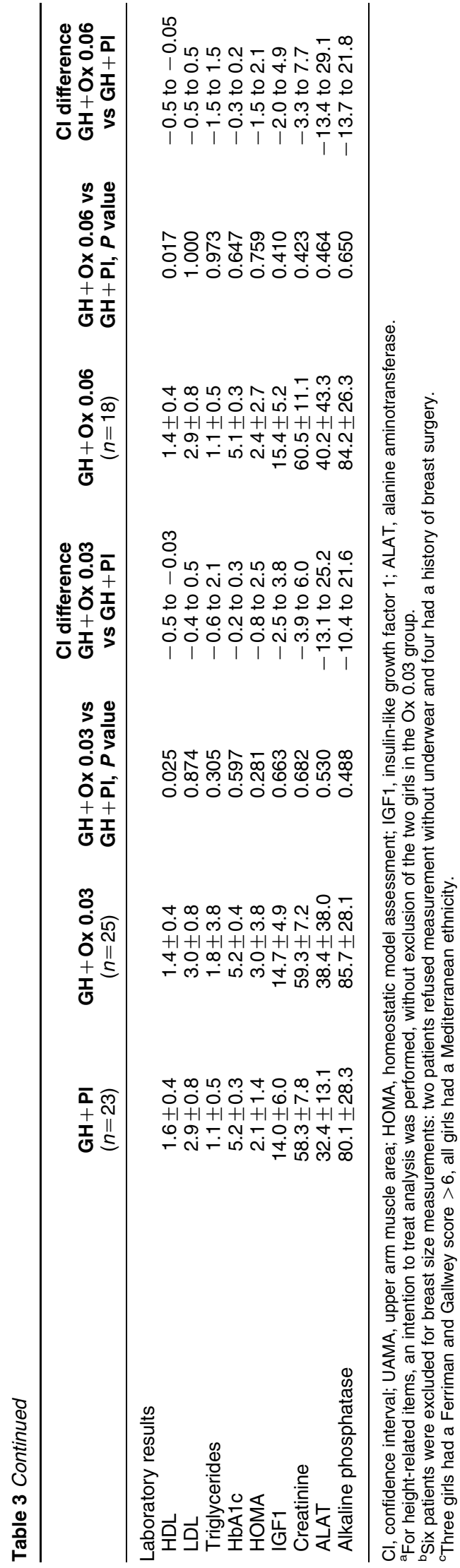

reported a subjective delay of breast development in puberty compared with peers, with equal distributions across groups. At the time of reassessment, five patients regarded breast size as being too small (one in the $\mathrm{GH}+\mathrm{Pl}$ group, three in the $\mathrm{GH}+\mathrm{Ox} 0.03$ group, and one in the $\mathrm{GH}+\mathrm{Ox} 0.06$ group).

\section{Subjective virilization}

Hirsutism was reported by 19 women $(\mathrm{GH}+\mathrm{Pl}, n=0$; $\mathrm{GH}+\mathrm{Ox} 0.03, n=9$; and $\mathrm{GH}+\mathrm{Ox} 0.06, n=10)$. The frequency was significantly higher in both $\mathrm{Ox}$ groups compared with Pl (Table 3). Acne was reported by five women $(\mathrm{GH}+\mathrm{Pl}, n=0$; $\mathrm{GH}+\mathrm{Ox} 0.03, n=4$; and $\mathrm{GH}+\mathrm{Ox} 0.06, n=1)$ and greasy skin by five $(\mathrm{GH}+\mathrm{Pl}$, $n=0 ; \mathrm{GH}+\mathrm{Ox} 0.03, n=3$; and $\mathrm{GH}+\mathrm{Ox} 0.06, n=2$ ). A low voice was reported by 15 women $(\mathrm{GH}+\mathrm{Pl}, n=6$; $\mathrm{GH}+\mathrm{Ox} 0.03, n=4$; and $\mathrm{GH}+\mathrm{Ox} 0.06, n=5)$ and clitoromegaly by two $(\mathrm{GH}+\mathrm{Pl}, n=2 ; \mathrm{GH}+\mathrm{Ox} 0.03$, $n=0$; and $\mathrm{GH}+\mathrm{Ox} 0.06, n=0)$. Women treated with Ox 0.03 or 0.06 had a relative risk of $1.4(P=0.342)$ and $2.4(P=0.004)$ respectively to report one or more virilizing effects.

\section{Objective virilization}

Hirsutism, defined as a Ferriman and Gallwey score above six, was confirmed objectively in three women $(\mathrm{GH}+\mathrm{Pl}, n=0$; $\mathrm{GH}+\mathrm{Ox} 0.03, n=2$; and $\mathrm{GH}+\mathrm{Ox} 0.06$, $n=1)$. None of them had elevated androgen levels. Women in both Ox groups had a lower mean voice frequency compared with the Pl group. Nine women had a voice frequency below the reference values for both counting backward and reading standardized sentences $(\mathrm{GH}+\mathrm{Pl}, n=2 ; \mathrm{GH}+\mathrm{Ox} 0.03, n=5 ; \mathrm{GH}+$ Ox $0.06, n=2$; and mean voice frequency $189.1 \pm 6.9)$. Three $(\mathrm{GH}+\mathrm{Ox} 0.03, n=1$ and $\mathrm{GH}+\mathrm{Ox} 0.06, n=2)$ had objective evidence of mild clitoromegaly (clitoral size just over $1 \mathrm{~cm}$ ). Four patients had more than one sign of virilization: two in the $\mathrm{GH}+\mathrm{Ox} 0.03$ group (one patient with a greasy skin, acne, hirsutism, and a low voice and one patient with acne, hirsutism, and a low voice) and two in the $\mathrm{GH}+\mathrm{Ox} 0.06$ group (one patient with clitoromegaly and low voice and one with greasy skin, acne, and hirsutism).

\section{Correlation between subjective and objective virilizations}

Virilization was objectively confirmed in a minority of patients with subjective symptoms. The proportions of objective virilization in patients with subjective symptoms were as follows: hirsutism 3/19, greasy skin 3/5, acne $5 / 5$, clitoromegaly $0 / 2$, and low voice $4 / 15$. Patients who reported a low voice were confirmed to have a lower mean voice frequency than those who reported a normal or high voice $(205.5$ vs $219.5 \mathrm{~Hz}$, $P=0.016)$. Vice versa, actual virilization was recognized 
in most cases, except for clitoromegaly. The proportions of patients with subjective symptoms in cases of objective virilization were as follows: hirsutism 3/3, greasy skin $3 / 3$, acne $5 / 8$, clitoromegaly $0 / 3$, and low voice $4 / 9$.

\section{Laboratory investigations}

The lipid spectrum was equal in all groups, except for HDL cholesterol, which was lower in both Ox groups compared with Pl (Table 3). Ten patients, equally distributed in the treatment modalities, had a HDL below $1.10 \mathrm{mmol} / \mathrm{l}$. Thyroid function, after exclusion of 11 levothyroxine users, was similar between groups. Glucose metabolism did not differ between the treatment groups. There was one patient with type 2 diabetes in the $\mathrm{GH}+\mathrm{Ox} 0.03$ group. All patients had a creatinine level within the reference values. Ten patients had one or more liver enzymes above twice the upper reference limit: three in the Pl group (13.0\%), four in the $\mathrm{GH}+\mathrm{Ox} 0.03$ group $(16.0 \%)$, and three in the $\mathrm{GH}+\mathrm{Ox} 0.06$ group $(16.7 \%)$.

\section{Discussion}

We present the long-term outcome of a Dutch multicenter trial on the effects of $\mathrm{Ox}$ (besides GH and estrogen) in girls with TS. We have shown that the positive effect of $\mathrm{Ox}$ in a dosage of $0.03 \mathrm{mg} / \mathrm{kg}$ per day on adult height gain found in the pediatric study has been maintained. The initial study showed a mild deceleration of breast development, mild subjective virilization, and a lower voice frequency due to Ox. Our current findings indicate that the deceleration of breast development during Ox treatment is transient. In the long-term study, final breast size and Tanner stage were similar between the $\mathrm{Ox}$ and $\mathrm{Pl}$ groups. The Ox-treated adult women still reported more subjective virilization, but actual virilization was only confirmed objectively in a few cases.

Besides our study, two placebo-controlled trials have confirmed an increase in height gain with $\mathrm{Ox}(8,12$, 14). The mechanism by which Ox influences growth is unclear. A positive effect on the growth plate as well as effects via other growth factors such as IGF1 have been suggested $(25,26)$. Data of our original study and the US study point toward a dose-dependent effect of Ox on bone maturation $(8,12)$. However, others could not confirm a faster bone maturation during Ox treatment when using a dosage of $0.05 \mathrm{mg} / \mathrm{kg}$ per day, with a maximum Ox dose of $2.5 \mathrm{mg}$ daily (14).

Previous studies in TS girls using Ox dosages of $\sim 1 \mathrm{mg} / \mathrm{kg}$ per day found that these dosages frequently needed to be lowered due to virilization $(9,10,11)$. In our study as well as in the US study, virilization was more frequently seen in girls treated with $\mathrm{Ox}$ than $\mathrm{Pl}$, particularly with $\mathrm{Ox} 0.06(8,12)$. Gynecological examination revealed three patients with mild clitoromegaly, and although the numbers are too small to allow conclusions, it is noteworthy that all three patients had been treated with Ox. Furthermore, there were three other Ox-treated women, all of Mediterranean origin, with overt (though mild) hirsutism. We speculate that this hirsutism was mainly related to ethnicity but we cannot rule out an effect of Ox. Even in the cases without hirsutism, we still found a small yet significant dose-dependent effect of $\mathrm{Ox}$ on androgendependent body hair. This is in line with increased subjective scores of hair growth. The lower voice frequency observed in girls treated with $\mathrm{Ox}$ in our pediatric study confirmed the data of a cross-sectional study on Ox from Sweden (27). As expected, the voice changes were irreversible and we confirmed the dosedependent lower mean voice frequencies in the Ox 0.06 treated group. However, mean voice frequencies of both Ox-treated groups are normal. Remarkably, no virilizing effects were found in the UK study of 106 TS girls treated with $\mathrm{Ox}$ in a dosage of $0.05 \mathrm{mg} / \mathrm{kg}$ per day with a maximum of $2.5 \mathrm{mg} /$ day (14). A possible reason for this discrepancy with our study might be the use of a maximum $\mathrm{Ox}$ dose and also the lack of systematic assessments of virilization in that study.

Although pubertal induction with low-dose estrogens starting at 12 years of age seems to be appropriate, half of the patients reported delayed breast development. Consequently, a further delay of breast development due to Ox (observed in the US study as well as in our pediatric study, while not specifically assessed in the UK study) is undesirable $(8,12,14)$. Theoretically, Ox inhibits the estrogen effect on breast development (28). Our follow-up study, however, showed no differences in subjective breast development between the treatment groups. Furthermore, final breast size and Tanner stage were similar in both $\mathrm{Ox}$ and $\mathrm{Pl}$ groups, indicating that the effect of $\mathrm{Ox}$ on breast development is transient. This is in line with the improvement of breast stage SDS after discontinuation of Ox seen in our pediatric study (12).

Theoretically, Ox could affect body composition in a beneficial way. In general, women with TS tend to have an increase in BMI and fat mass including visceral fat $(29,30,31)$. In a pilot study in adult women with TS, androgen treatment increased lean body mass and decreased fat mass (32). In our pediatric study, we also showed a reduction in fat mass and an increment in muscle mass during Ox treatment (15). In our current study, however, we did not find any differences in body composition. We found a small reduction of HDL cholesterol in the Ox-treated groups. This is in line with a recent study on the use of methyltestosterone in adult women with TS, although in that study the decrease in HDL during treatment was accompanied by a reduction of total cholesterol and triglycerides resulting in a more favorable lipid profile (32). Also in the US study, the decrease in HDL was accompanied by a decrease in triglycerides (8). As women with TS in 
general have an unfavorable cardiovascular risk profile, this may be an important issue (33).

Regarding body proportions, TS women have relatively shorter legs, larger hands and feet, and broader shoulders and pelvis (34). GH treatment has a beneficial effect on the disproportion between total height and sitting height $(34,35)$. Ox, however, seemed to negatively influence this disproportionality. In the pediatric study, we found a significant increase in sitting height/height ratio in the Ox-treated groups, which was confirmed for the Ox 0.06 group at long-term follow-up. Furthermore, the notion that $\mathrm{Ox}$ increases biacromial distance and decreases biiliacal distance is confirmed in our adult population, although the numbers did not reach statistical significance.

An important limitation of the current study is that only half of the original participants could be included for the follow-up. We cannot rule out that certain differences between the treatment groups remained undetected due to lack of power. For example, the difference in height gain favoring Ox 0.03 observed in the full cohort failed to reach statistical significance $(P=0.094)$ in the follow-up study. The number of dropouts was equally distributed among the treatment arms, suggesting that the sample remains representative of the cohort. However, the participants of the follow-up study had a larger height gain at last pediatric follow-up as well as a longer duration of Ox treatment than the nonparticipants. This may have affected the outcome. Also, we cannot rule out that possible differences in spontaneous puberty, although not significant, have impacted long-term effects.

Our study is the first long-term follow-up study on the effects of Ox in TS patients. Based on our previous and current findings, we conclude that $\mathrm{Ox} 0.06 \mathrm{mg} / \mathrm{kg}$ per day should not be used in girls with TS as there is no significant effect on adult height and it results in (nonreversible) virilizing effects. Ox $0.03 \mathrm{mg} / \mathrm{kg}$ per day in addition to $\mathrm{GH}$ and estrogen treatment has a beneficial effect on adult height gain in TS patients. Despite previously reported deceleration of breast development during Ox 0.03 treatment, eventual adult breast size is not affected. We conclude that $\mathrm{Ox}$ in this dosage can be safely used in girls with TS, although usually mild virilization can persist in a minority of patients. We therefore recommend careful counseling before the start of Ox. Currently, Ox is not universally available in Europe. Our study might contribute to the reintroduction of Ox. Long-term follow-up, including assessment of cardiovascular and uterine status, is necessary to assess effects of $\mathrm{Ox}$ even in the longer term.

\section{Declaration of interest}

The authors declare that there is no conflict of interest that could be perceived as prejudicing the impartiality of the research reported.

\section{Funding}

A R M M Hermus and H J L M Timmers received a research grant from Pfizer for this research. T C J Sas received lecture fees from Novo Nordisk and Pfizer and did advisory work for Novo Nordisk. J M Wit has served on the advisory boards of Pfizer, Ipsen, Versartis, Prolor, and Biopartners. J M Wit received fees from Pfizer, Ipsen, and Ferring. L A Menke received honorarium for her thesis from Pfizer, Eli Lilly, ACE pharmaceuticals, Ferring, Novo Nordisk, Ipsen, and Sandoz. This work was supported by Pfizer. The funding organization had no role in the design, conduction, and reporting of the study.

\section{References}

1 Nielsen J \& Wohlert M. Sex chromosome abnormalities found among 34,910 newborn children: results from a 13-year incidence study in Arhus, Denmark. Birth Defects Original Article Series 199026 209-223.

2 Rongen-Westerlaken C, Corel L, van den Broeck J, Massa G, Karlberg J, Albertsson-Wikland K, Naeraa RW \& Wit JM. Reference values for height, height velocity and weight in Turner's syndrome. Swedish Study Group for GH treatment. Acta Paediatrica 199786 937-942. (doi:10.1111/j.1651-2227.1997.tb15174.x)

3 Stephure DK. Impact of growth hormone supplementation on adult height in Turner syndrome: results of the Canadian randomized controlled trial. Journal of Clinical Endocrinology and Metabolism 200590 3360-3366. (doi:10.1210/jc.2004-2187)

4 Van Pareren YK, de Muinck Keizer-Schrama SM, Stijnen T, Sas TC, Jansen M, Otten BJ, Hoorweg-Nijman JJ, Vulsma T, StokvisBrantsma WH, Rouwe CW et al. Final height in girls with Turner syndrome after long-term growth hormone treatment in three dosages and low dose estrogens. Journal of Clinical Endocrinology and Metabolism 200388 1119-1125. (doi:10.1210/jc.2002021171)

5 Sas TC, de Muinck Keizer-Schrama SM, Stijnen T, Jansen M, Otten BJ, Hoorweg-Nijman JJ, Vulsma T, Massa GG, Rouwe CW, Reeser HM et al. Normalization of height in girls with Turner syndrome after long-term growth hormone treatment: results of a randomized dose-response trial. Journal of Clinical Endocrinology and Metabolism $1999 \mathbf{8 4}$ 4607-4612. (doi:10. $1210 /$ jc.84.12.4607)

6 Hamelin CE, Anglin G, Quigley CA \& Deal CL. Genomic imprinting in Turner syndrome: effects on response to growth hormone and on risk of sensorineural hearing loss. Journal of Clinical Endocrinology and Metabolism 200691 3002-3010. (doi:10.1210/ jc.2006-0490)

7 Binder G, Trebar B, Baur F, Schweizer R \& Ranke MB. Homozygosity of the d3-growth hormone receptor polymorphism is associated with a high total effect of GH on growth and a low BMI in girls with Turner syndrome. Clinical Endocrinology 200868 567-572. (doi:10.1111/j.1365-2265.2007.03090.x)

8 Zeger MP, Shah K, Kowal K, Cutler GB Jr, Kushner H \& Ross JL. Prospective study confirms oxandrolone-associated improvement in height in growth hormone-treated adolescent girls with Turner syndrome. Hormone Research in Paediatrics 201175 38-46. (doi:10.1159/000317529)

9 Rosenfeld RG, Attie KM, Frane J, Brasel JA, Burstein S, Cara JF, Chernausek S, Gotlin RW, Kuntze J, Lippe BM et al. Growth hormone therapy of Turner's syndrome: beneficial effect on adult height. Journal of Pediatrics 1998132 319-324. (doi:10.1016/ S0022-3476(98)70452-4)

10 Nilsson KO, Albertsson-Wikland K, Alm J, Aronson S, Gustafsson J, Hagenas L, Hager A, Ivarsson SA, Karlberg J, Kristrom B et al. Improved final height in girls with Turner's syndrome treated with growth hormone and oxandrolone. Journal of Clinical Endocrinology and Metabolism 199681 635-640. (doi:10.1210/ jc.81.2.635)

11 Stahnke N, Keller E \& Landy H. Favorable final height outcome in girls with Ullrich-Turner syndrome treated with low-dose growth 
hormone together with oxandrolone despite starting treatment after 10 years of age. Journal of Pediatric Endocrinology $\mathcal{E}$ Metabolism 200215 129-138.

12 Menke LA, Sas TC, de Muinck Keizer-Schrama SM, Zandwijken GR, de Ridder MA, Odink RJ, Jansen M, Delemarrevan de Waal HA, Stokvis-Brantsma WH, Waelkens JJ et al. Efficacy and safety of oxandrolone in growth hormone-treated girls with Turner syndrome. Journal of Clinical Endocrinology and Metabolism 201095 1151-1160. (doi:10.1210/jc.2009-1821)

13 Haeusler G, Schmitt K, Blumel P, Plochl E, Waldhor T \& Frisch H. Growth hormone in combination with anabolic steroids in patients with Turner syndrome: effect on bone maturation and final height. Acta Paediatrica 199685 1408-1414.

14 Gault EJ, Perry RJ, Cole TJ, Casey S, Paterson WF, Hindmarsh PC, Betts P, Dunger DB \& Donaldson MD. Effect of oxandrolone and timing of pubertal induction on final height in Turner's syndrome: randomised, double blind, placebo controlled trial. BMJ 2011342 d1980. (doi:10.1136/bmj.d1980)

15 Menke LA, Sas TC, Zandwijken GR, de Ridder MA, Stijnen T, de Muinck Keizer-Schrama SM, Otten BJ \& Wit JM. The effect of oxandrolone on body proportions and body composition in growth hormone-treated girls with Turner syndrome. Clinical Endocrinology 201073 212-219. (doi:10.1111/j.1365-2265. 2010.03789.x)

16 Menke LA, Sas TC, van Koningsbrugge SH, de Ridder MA, Zandwijken GR, Boersma B, Dejonckere PH, de Muinck KeizerSchrama SM, Otten BJ \& Wit JM. The effect of oxandrolone on voice frequency in growth hormone-treated girls with Turner syndrome. Journal of Voice $2011 \mathbf{2 5} 602-610$. (doi:10.1016/ j.jvoice.2010.06.002)

17 Lyon AJ, Preece MA \& Grant DB. Growth curve for girls with Turner syndrome. Archives of Disease in Childhood $1985 \mathbf{6 0}$ 932-935. (doi:10.1136/adc.60.10.932)

18 Gerver W. Paediatric Morphometrics. A Reference Manual (second extended edition). Universitaire Pers Maastricht, 2001.

19 Frisancho AR. New norms of upper limb fat and muscle areas for assessment of nutritional status. American Journal of Clinical Nutrition $1981342540-2545$.

20 Durnin JV \& Womersley J. Body fat assessed from total body density and its estimation from skinfold thickness: measurements on 481 men and women aged from 16 to 72 years. British Journal of Nutrition 197432 77-97. (doi:10.1079/BJN19740060)

21 Marshall WA \& Tanner JM. Variations in pattern of pubertal changes in girls. Archives of Disease in Childhood $196944291-303$. (doi:10.1136/adc.44.235.291)

22 van Zuuren EJ \& Pijl H. Hirsutism. Ned Tijdschr Geneeskd 2007151 2313-2318.

23 Traunmüller $\mathrm{H}$ \& Eriksson A. The frequency range of the voice fundamental in the speech of male and female adults. Stockholm: University of Stockholm, 1995.

24 Matthews DR, Hosker JP, Rudenski AS, Naylor BA, Treacher DF \& Turner RC. Homeostasis model assessment: insulin resistance and $\beta$-cell function from fasting plasma glucose and insulin concentrations in man. Diabetologia $1985 \mathbf{2 8} 412-419$. (doi:10.1007/ BF00280883)

25 Chagin AS, Vannesjo J \& Savendahl L. Androgen receptor modulation does not affect longitudinal growth of cultured fetal rat metatarsal bones. Hormone Research 200971 219-227. (doi:10.1159/000201111)
26 Haeusler G, Schmitt K, Blumel P, Plochl E, Waldhor T \& Frisch H. Insulin, insulin-like growth factor-binding protein-1, and sex hormone-binding globulin in patients with Turner's syndrome: course over age in untreated patients and effect of therapy with growth hormone alone and in combination with oxandrolone. Journal of Clinical Endocrinology and Metabolism 199681 536-541. (doi:10.1210/jc.81.2.536)

27 Andersson-Wallgren G, Ohlsson AC, Albertsson-Wikland K \& Barrenas ML. Growth promoting treatment normalizes speech frequency in Turner syndrome. Laryngoscope $20081181125-1130$. (doi:10.1097/MLG.0b013e31816927de)

28 Labrie F. Dehydroepiandrosterone, androgens and the mammary gland. Gynecological Endocrinology 200622 118-130. (doi:10.1080/09513590600624440)

29 Gravholt CH, Naeraa RW, Fisker S \& Christiansen JS. Body composition and physical fitness are major determinants of the growth hormone-insulin-like growth factor axis aberrations in adult Turner's syndrome, with important modulations by treatment with 17ß-estradiol. Journal of Clinical Endocrinology and Metabolism $1997 \mathbf{8 2}$ 2570-2577. (doi:10.1210/jc.82.8. 2570)

30 Holl RW, Kunze D, Etzrodt H, Teller W \& Heinze E. Turner syndrome: final height, glucose tolerance, bone density and psychosocial status in 25 adult patients. European Journal of Pediatrics 1994153 11-16. (doi:10.1007/BF02000780)

31 Ostberg JE, Thomas EL, Hamilton G, Attar MJ, Bell JD \& Conway GS. Excess visceral and hepatic adipose tissue in Turner syndrome determined by magnetic resonance imaging: estrogen deficiency associated with hepatic adipose content. Journal of Clinical Endocrinology and Metabolism 200590 2631-2635. (doi:10.1210/jc.2004-1939)

32 Zuckerman-Levin N, Frolova-Bishara T, Militianu D, Levin M, Aharon-Peretz J \& Hochberg Z. Androgen replacement therapy in Turner syndrome: a pilot study. Journal of Clinical Endocrinology and Metabolism 200994 4820-4827. (doi:10. 1210/jc.2009-0514)

33 Kozlowska-Wojciechowska M, Jez W, Zdrojewski T \& Chwojnicki K. Are young women with Turner syndrome at greater risk of coronary artery disease? European Journal of Cardiovascular Prevention and Rehabilitation 200613 467-469. (doi:10.1097/01.hjr.0000216545.99807.fd)

34 Sas TC, Gerver WJ, de Bruin R, Stijnen T, de Muinck KeizerSchrama SM, Cole TJ, van Teunenbroek A \& Drop SL. Body proportions during long-term growth hormone treatment in girls with Turner syndrome participating in a randomized doseresponse trial. Journal of Clinical Endocrinology and Metabolism 199984 4622-4628. (doi:10.1210/jc.84.12.4622)

35 Bannink EM, van der Palen RL, Mulder PG \& de Muinck Keizer-Schrama SM. Long-term follow-up of GH-treated girls with Turner syndrome: BMI, blood pressure, body proportions. Hormone Research 200971 336-342. (doi:10.1159/000223418)

Received 8 May 2012

Revised version received 26 September 2012

Accepted 17 October 2012 